\title{
Planting a Problem: Examining the Spread of Seed-Borne Potato Virus $Y$
}

\author{
Jeremy Rosenman, ${ }^{1, \dagger}$ Christopher S. McIntosh, ${ }^{1}{ }^{\text {Giri Raj Aryal, }}{ }^{2}$ and Phil Nolte ${ }^{3}$ \\ ${ }^{1}$ Agricultural Economics and Rural Sociology, University of Idaho, Moscow, ID 83844 \\ ${ }^{2}$ Michigan State University, East Lansing, MI \\ ${ }^{3}$ Plant Pathology, University of Idaho, Moscow, ID 83844
}

\begin{abstract}
Potato virus $\mathrm{Y}(\mathrm{PVY})$ is among the most economically impactful potato pathogens, yet the spread of PVY from infected seed potatoes within commercial potato fields has not been adequately studied. Test lots containing various seed-borne PVY levels were created by mixing different proportions of seed pieces from healthy and infected tubers

infected seed. Conventional ordinary least squares techniques were supplemented with the use of quantile regression; the resulting models indicate the significance of seed-borne PVY on end-of-season infection levels and highlight the need of seed potato buyers to review postharvest testing results.
\end{abstract} drawn from the same seed source. These seed lots were planted in commercial potato fields near the Teton Seed Potato Management Area from 2010 to 2012. Regression analyses on data from these test plots produced models of the in-season spread of PVY originating from
Keywords: viruses, vegetables, disease management, cultural and biological practices, epidemiology, disease development and spread, yield loss and economic impacts
Potato virus Y (PVY), type virus of the family Potyviridae, is an important plant pathogenic virus distributed worldwide whose host range includes many economically important crops such as potato, tobacco, tomato, pepper, and so on. Several previous studies on PVY and how it impacts potato production have demonstrated that the virus reduces yield in many of the potato cultivars commonly produced in the United States (Bonde et al. 1943; Mondjana et al. 1993). The effects of PVY are most detrimental when the harvested potatoes are rendered unmarketable owing to the occurrence of potato tuber necrotic ring-spot disease, which is caused by the tuber necrotic strain of PVY (PVY ${ }^{N T N}$ ) identified in North America (Gray et al. 2010).

PVY may cause yield losses as high as $80 \%$ (Hane and Hamm 1999); as such, significant effort is expended worldwide to produce seed potatoes containing low levels (no more than $2 \%$ infection rate) of this virus. Some varieties, such as 'Russet Norkotah' and 'Shepody', have only mild or latent symptoms, as opposed to the typical foliar mosaic symptoms that are readily observed in 'Russet Burbank' and other cultivars (Nolte et al. 2009; Zeng et al. 2019). In the past decades the emergence of new PVY strains within the United States (Funke et al. 2017), inconsistent use of suitable diagnostic tools, and the release of asymptomatic cultivars has hampered the efficiency of seed certification inspections and may have led to an increased virus level in seed stocks (Karasev and Gray 2013).

PVY is a persistent problem for seed certification and is responsible for a significant share of seed lot rejections in numerous states (Frost et al. 2013; Schramm et al. 2011; Zeng et al. 2019). The

\section{${ }^{\dagger}$ Corresponding author: J. Rosenman; rose2196@vandals.uidaho.edu}

Funding: This research was supported by the University of Idaho Agricultural Experiment Station and the USDA through Hatch Project 10102804 and SCRI project 2014-51181-22373.

The author(s) declare no conflict of interest.

Accepted for publication 21 April 2019.

() 2019 The American Phytopathological Society presence of several noncolonizing cereal aphids such as Rhopalosiphum maidis, Rhopalosiphum padi, and Schizaphis graminum virtually ensures the spread of PVY that is already present in a potato field (i.e., that which is contained in the seed potatoes that were planted). It has been suggested that noncolonizing aphids are the main cause behind poor control of PVY (Halbert et al. 2003). As such, seed-borne PVY continues to be a chronic problem for potato growers in Idaho and elsewhere in the United States.

Nolte et al. (2004) reported yield reductions owing to seed-borne PVY infections of $196 \mathrm{~kg} / \mathrm{ha}$ for each percent of PVY infection in Russet Burbank. Similarly, they found that Russet Norkotah and Shepody yields were reduced by 167 and $160 \mathrm{~kg} / \mathrm{ha}$ per percent increase in PVY infection, respectively. More recently, Aryal (2013) has indicated that the marketable yield of Russet Norkotah potatoes was reduced by $131 \mathrm{~kg} / \mathrm{ha}$ for each percentage point of seed-borne PVY, resulting in a $\$ 30.32 /$ ha reduction in gross revenues per percentage point of PVY infection (when evaluated using fresh-pack prices). Aryal also found that Russet Burbank marketable yields were reduced by $137 \mathrm{~kg} / \mathrm{ha}$ per percentage point of PVY infection, and (when evaluated using fresh-pack prices) gross revenues were reduced by $\$ 22.66 /$ ha per percentage point of PVY infection.

Given all of this, it is obvious that PVY poses a problem for producers of commercial potatoes. The purpose of this paper is to examine the relationship between PVY present in seed potatoes at planting (seed-borne PVY level) and the level of PVY in the crop at the time of harvest. We first examine the in-season and postharvest test results from three states (Wisconsin, Montana, and Idaho), focusing on how summer field inspection and postharvest test results compare with each other. We then model the in-season spread of PVY originating from infected seed potatoes using experimental data from test plots planted in southeastern Idaho.

\section{Materials and Methods}

The in-season visual mosaic readings and postharvest laboratory test results by lot and variety for certified seed potatoes in Wisconsin were provided by the Wisconsin Seed Potato Certification program at the University of Wisconsin, Madison; data for Idaho-grown certified seed potatoes were provided by the Idaho Crop Improvement Association. Data from the Montana Seed Potato Certification Program using enzyme-linked immunosorbent assay testing for both 
summer and postharvest tests were also provided. The Wisconsin data were for 2003 to 2010, Montana for 2001 to 2003 and 2005 to 2010, and the Idaho data for 2009 to 2010.

Because the data set contains a large number of observations with a value of zero, it is difficult to analyze the data set statistically. Thus, we considered the occurrence of two events by variety. The first was seed lots for which the postharvest tests detected a higher level of PVY infection than the summer tests. The second event was seed lots for which the summer tests detected PVY of less than 2\% PVY/ mosaic (depending on in-season testing methodology used) whereas the postharvest tests measured PVY levels greater than $2 \%$.

As part of a larger experiment, an effort was made to assess the degree to which the levels of PVY as measured at the end of the growing season relate to the level of PVY infection in the planted seed potatoes. Experimental data from test plots planted in commercial potato fields in southeastern Idaho and cultivated according to established protocols were used for this analysis. The experiment was conducted on two important potato cultivars: Russet Burbank and Russet Norkotah. The experiments were conducted during three consecutive years from 2010 to 2012 .

For the field portion of the study, experimental plots containing various target levels of PVY were artificially created for each variety in each of the three years of the study, by collecting 350 - to $400-\mathrm{kg}$ samples $(2,100$ or more seed tubers) from certified seed lots containing known levels of PVY. Candidate seed lots were identified using postharvest test results obtained from the Idaho Crop Improvement Association. Virus status of individual tubers was determined by removing three to five lateral buds from each tuber using a 5-mm cork borer, combining the eyes from a single tuber into a composite sample, and testing with enzyme-linked immunosorbent assay (ELISA). Tubers testing positive were kept separate from those testing negative. Because the tested tubers were to be divided into seed pieces weighing between 50 and $70 \mathrm{~g}$, fewer buds were removed from smaller tubers to ensure sufficient tuber tissue and enough buds remained to obtain seed pieces in the desired size range. No whole tubers were used for this study; every tested tuber was cut at least once. Tubers from the healthy and PVY-infected portions of the tested seed lots were hand cut into seed pieces and, to avoid seed piece decay, treated with a seed treatment dust formulation containing a combination of imidacloprid, thiophanate-methyl, and mancozeb (Tops MZ-Gaucho, Bayer CropScience, Plano, TX). Healthy and infected seed pieces were placed randomly into paper bags ( 20 seed

Table 1. Russet Burbank test plot treatment targets and actual percentage of seed infected with potato virus Y (PVY) by year

\begin{tabular}{|c|c|c|c|c|c|c|}
\hline \multirow[b]{2}{*}{ Treatment } & \multicolumn{2}{|c|}{2010} & \multicolumn{2}{|c|}{2011} & \multicolumn{2}{|c|}{2012} \\
\hline & $\begin{array}{l}\text { Target } \\
\text { PVY }\end{array}$ & $\begin{array}{l}\text { Tested } \\
\text { PVY }^{\mathbf{a}}\end{array}$ & $\begin{array}{l}\text { Target } \\
\text { PVY }\end{array}$ & $\begin{array}{l}\text { Tested } \\
\text { PVY }^{\mathbf{a}}\end{array}$ & $\begin{array}{c}\text { Target } \\
\text { PVY }\end{array}$ & $\begin{array}{l}\text { Tested } \\
\text { PVY }^{\mathbf{a}}\end{array}$ \\
\hline 1 & $0 \%$ & $4.4 \%$ & $0 \%$ & $12.0 \%$ & $0 \%$ & $6.9 \%$ \\
\hline 2 & $5 \%$ & $10.2 \%$ & $5 \%$ & $13.8 \%$ & $5 \%$ & $10.8 \%$ \\
\hline 3 & $10 \%$ & $16.3 \%$ & $10 \%$ & $13.1 \%$ & $15 \%$ & $17.2 \%$ \\
\hline 4 & $25 \%$ & $30.2 \%$ & $25 \%$ & $30.9 \%$ & $30 \%$ & $30.5 \%$ \\
\hline 5 & $50 \%$ & $51.3 \%$ & $50 \%$ & $49.7 \%$ & NA & NA \\
\hline
\end{tabular}

${ }^{a}$ The average for the treatment.

Table 2. Russet Norkotah test plot treatment targets and actual percentage of seed infected with potato virus Y (PVY) by year

\begin{tabular}{lrrrrrrrr}
\hline & \multicolumn{2}{c}{$\mathbf{2 0 1 0}$} & & \multicolumn{2}{c}{$\mathbf{2 0 1 1}$} & & \multicolumn{2}{c}{$\mathbf{2 0 1 2}$} \\
\cline { 2 - 3 } Treatment & $\begin{array}{c}\text { Target } \\
\text { PVY }\end{array}$ & $\begin{array}{c}\text { Tested } \\
\text { PVY }^{\mathbf{a}}\end{array}$ & & $\begin{array}{c}\text { Target } \\
\text { PVY }\end{array}$ & $\begin{array}{c}\text { Tested } \\
\text { PVY }^{\mathbf{a}}\end{array}$ & & $\begin{array}{c}\text { Target } \\
\text { PVY }\end{array}$ & $\begin{array}{c}\text { Tested } \\
\text { PVY }^{\mathbf{2}}\end{array}$ \\
\hline 1 & $0 \%$ & $1.9 \%$ & & $0 \%$ & $8.2 \%$ & & $0 \%$ & $1.3 \%$ \\
2 & $5 \%$ & $7.7 \%$ & & $5 \%$ & $14.7 \%$ & & $5 \%$ & $8.2 \%$ \\
3 & $10 \%$ & $8.1 \%$ & & $10 \%$ & $22.0 \%$ & & $10 \%$ & $14.5 \%$ \\
4 & $25 \%$ & $26.3 \%$ & & $25 \%$ & $31.5 \%$ & & $25 \%$ & $29.3 \%$ \\
5 & $50 \%$ & $50.0 \%$ & & $50 \%$ & $58.3 \%$ & & $50 \%$ & $51.3 \%$ \\
\hline
\end{tabular}

${ }^{a}$ The average for the treatment. pieces per bag, for a total of 40 seed pieces per plot) in the desired target ratios for each respective plot. For example, two infected seed pieces combined with 38 that tested as healthy yielded plots containing 5\% PVY, whereas four infected seed pieces combined with 36 that tested as healthy yielded plots containing $10 \%$ PVY.

The data were generated in plots established using a randomized complete block design. Seed pieces were planted in paired rows of 20 seed pieces each, and each plot included a one-row border, on both sides, planted with tubers obtained from the respective donor seed lots. In 2010, seed was cut, treated, and combined in the desired ratios of healthy to PVY-infected seed pieces (blended) on May 11 and planted on May 26. For 2011, seed was cut, treated, and blended on May 20 and, because of a rain delay, not planted until June 2. For 2012, seed was cut, treated, and blended on May 8 and planted on May 10. In all three years, PVY target levels for both varieties were $0,5,10,25$, and 50\% seed-borne PVY. In 2010, a single leaflet from each emerged plant in each plot was removed for PVY testing on July 20 (to determine emergence PVY levels), and end-of-season samples were picked September 2 for Russet Norkotah and September 7 for Russet Burbank. In 2011, the early sampling was performed July 20, with end-of-season samples taken on September 6 . The early sample date for 2012 was July 2 for both varieties, and the late dates were August 29 for Russet Norkotah and September 5 for Russet Burbank. ELISA testing on individual leaves was performed within 2 days after samples were collected. Actual percentages of virus recorded for each plot rather than target percentages were used in the statistical analysis. Vines were allowed to senesce naturally and/or were killed by frost. On the date of harvest, vines were stripped from the plots by hand. Plots were harvested with a two-row chain-link potato lifter on September 29, 2010; September 28, 2011; and September 24, 2012. Tubers brought to the soil surface by the lifter were harvested by hand into $50-\mathrm{kg}$ burlap bags. Bags were weighed and tubers were graded, also by hand, on September 30 to October 1, 2010; September 29 to 30, 2011; and September 25 to October 1, 2012.

The Russet Burbank field trial consisted of five treatments with four replications of each; owing to lower than expected amounts of virus in the seed lot selected as a seed source in 2012, only four treatments were used that year. Russet Norkotah trials consisted of five treatments with four replications of each for all three years of the study. Each treatment had a target level of seed-borne PVY; ELISA tests showed the average seed-borne PVY of the four replications in each treatment to vary from the target levels as summarized for Russet Burbank test plots (Table 1) and for Russet Norkotah test plots (Table 2). For both varieties, the PVY infection level of each of the replications was again measured with ELISA at the end of the growing season. These data (Figs. 1 and 2) were used to model the spread of seed-borne PVY infections during the growing season. Regression analysis was used to determine the relationship between the two measured levels of PVY (seed-borne and end of season). This analysis was conducted in STATA using both ordinary least squares (OLS) and quantile regression techniques.

The complexity of variable interactions within ecological processes frequently leads to data that violate the underlying assumptions for OLS; using quantile regression techniques to analyze such data may be preferable to using OLS (Cade and Noon 2003). Because the residuals are not squared, quantile regression is more robust against outliers than ordinary least squares (Branham 1982; Edgeworth 1888). OLS is limited to evaluating the rate of change at the mean of the response variable distribution; this is a concern with regard to ecological data, for which unobserved limiting factors may induce heteroskedasticity through their interaction with observed variables (Cade et al. 1999). Quantile regression, as proposed by Koenker and Bassett (1978), offers significant improvement over OLS for distributions with non-Gaussian errors, distributions in which subsets of the population have different variances.

Quantile regression is an extension of least absolute deviations, historically referred to as the "method of minimum sums" (Edgeworth 1888). Least absolute deviation minimizes the sum of the absolute value of the residuals; in quantile regression analysis an asymmetrical 
penalty is imposed on the absolute value of residuals with the asymmetry increasing as the quantile approaches 0 or 1 . The quantile regression estimator $\left(\beta_{q}\right)$ for quantile $q$ minimizes the objective function:

$$
Q\left(\beta_{q}\right)=\sum_{i: y_{i} \geq x_{i}^{\prime} \beta}^{N} q\left|y_{i}-x_{i}^{\prime} \beta_{q}\right|+\sum_{i: y_{i}<x_{i}^{\prime} \beta}^{N}(1-q)\left|y_{i}-x_{i}^{\prime} \beta_{q}\right|, q \in(0,1)
$$

where $Q\left(\beta_{q}\right)$ is the conditional quantile function of quantile $q$. The quantile $q \in(0,1)$ is that $y$ which splits the data into proportions $q$ below and $1-q$ above such that $F\left(y_{q}\right)=q$ and $y_{q}=F^{-1}(q)$. The value of $y_{i}-x_{i}^{\prime} \beta_{q}$ is the residual $\grave{o}_{i}$ of observation $i ; x$ is an independent variable, the seed-borne PVY level; $y$ is the dependent variable, the end-ofseason PVY level within the field; and $\beta_{q}$ is a parameter to be estimated.

\section{Results}

Our analysis of in-season and postharvest test results was restricted to varieties for which there were 10 or more observations (Tables 3 and 4). For the varieties tabulated, in-season field inspections/tests measured a lower level of mosaic/PVY than the PVY infection level measured by postharvest tests 1 to $78 \%$ of the time, depending on state and variety. Using a nonweighted average across states, this was 10 to $65 \%$ of the time, depending on variety. This issue was more prevalent in Idaho and Wisconsin than in Montana; across common varieties the frequency in Montana was 55\% lower than in Idaho and $81 \%$ lower than in Wisconsin.

Postharvest tests reported a PVY infection rate of $>2 \%$ when the corresponding summer tests reported a mosaic/infection rate of $<2 \%$ between 0 and $26 \%$ of the time, depending on state and variety.

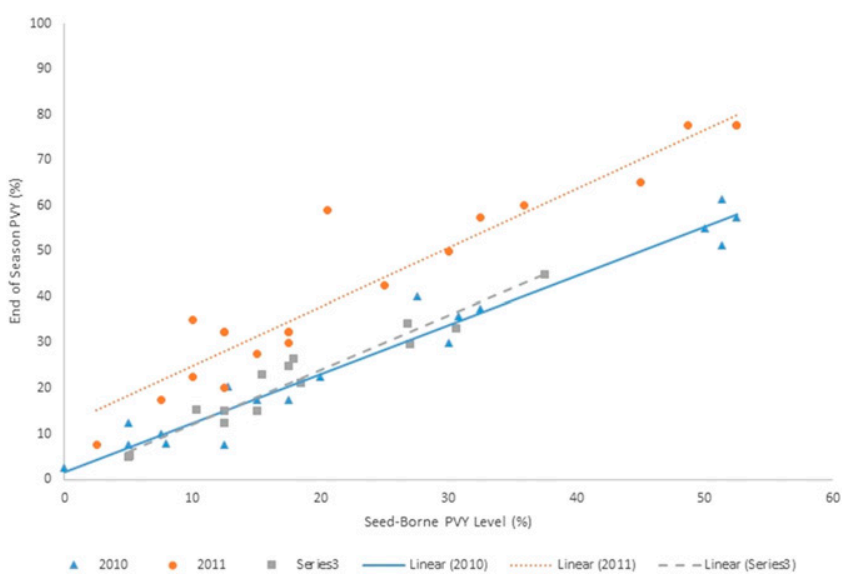

Fig. 1. Russet Burbank test plot seed-borne potato virus $Y(P V Y)$ infection levels versus end-of-season PVY infection levels by year.

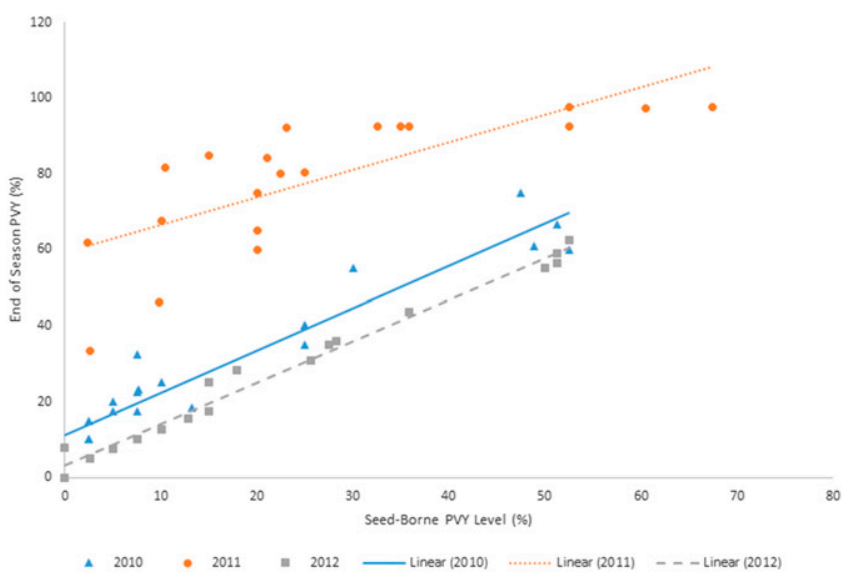

Fig. 2. Russet Norkotah test plot seed-borne potato virus $Y(P V Y)$ infection levels versus end-of-season PVY infection levels by year.
Again using a nonweighted average across states, this occurred 2 to $18 \%$ of the time, depending on variety. This issue was also more prevalent in Idaho and Wisconsin than in Montana; across common varieties the frequency in Montana was 64\% lower than in Idaho and $40 \%$ lower than in Wisconsin.

For each variety we generated five OLS models and five quantile models (Tables 5 and 6). Using OLS we modeled in-season PVY spread for all three years of experimental data and for each individual year. For both varieties we further used OLS to model in-season PVY spread using the combined 2010 and 2012 data. Using quantile regression, we modeled PVY spread for the 10th, 25th, 50th, 75th, and 95th quantiles. With only 20 observations per year (16 for 2012 Russet Burbank), we were unable to produce models with

Table 3. Percent of seed lots with postharvest tests detecting higher potato virus $\mathrm{Y}$ (PVY) levels than corresponding summer tests for selected states and varieties

\begin{tabular}{lccc}
\hline Variety & Wisconsin $^{\mathbf{a}}$ & Montana $^{\mathbf{b}}$ & Idaho $^{\mathbf{c}}$ \\
\hline Alturus & $\ldots$ & 16.0 & 50.0 \\
Atlantic & 60.8 & $\ldots$ & 66.7 \\
Amisk & $\ldots$ & 9.6 & \\
Dark Red Norland & 19.7 & 1.1 & 38.1 \\
Goldrush & 64.9 & $\ldots$ & $\ldots$ \\
Pike & 57.0 & $\ldots$ & $\ldots$ \\
Ranger Russet & $\ldots$ & 10.8 & 62.7 \\
Russet Burbank & 76.7 & 11.4 & 51.7 \\
Russet Norkotah & 77.7 & 32.1 & 22.0 \\
Shepody & $\ldots$ & 45.2 & 67.9 \\
Umatilla & $\ldots$ & 11.1 & 19.2 \\
Yukon Gold & 41.4 & 6.3 & 46.2 \\
\hline
\end{tabular}

${ }^{a}$ Wisconsin data were obtained for 2003 to 2010. Summer test PVY level inferred by mosaic symptoms; postharvest PVY level measured with ELISA.

${ }^{b}$ Montana data were obtained for 2001 to 2003 and 2005 to 2010. Summer and postharvest PVY level measured with ELISA.

${ }^{c}$ Idaho data were obtained for 2009 to 2010. Summer test PVY level inferred by mosaic symptoms; postharvest PVY level measured with ELISA.

d Amisk is a selection of Ranger Russet. Amisk data were provided separately by the Montana Seed Potato Certification program and were therefore considered separately in our analysis.

e Including the various Russet Norkotah selections.

Table 4. Percent of seed lots with postharvest tests detecting potato virus $Y$ (PVY) levels of $>2 \%$ whereas corresponding summer tests detected PVY levels of $<2 \%$ for selected states and varieties

\begin{tabular}{|c|c|c|c|}
\hline Variety & Wisconsin $^{\mathbf{a}}$ & Montana $^{b}$ & Idahoc \\
\hline Alturus & $\ldots$ & 5.0 & 8.0 \\
\hline Atlantic & 7.4 & $\ldots$ & 22.0 \\
\hline Amisk & $\ldots$ & 1.0 & ... \\
\hline Cal White & $\ldots$ & 9.0 & 26.3 \\
\hline Dark Red Norland & 7.7 & $\ldots$ & $\ldots$ \\
\hline Goldrush & 6.4 & $\ldots$ & $\ldots$ \\
\hline Pike & 2.2 & $\ldots$ & $\ldots$ \\
\hline Ranger Russet & $\ldots$ & 0.7 & 16.7 \\
\hline Russet Burbank & 10.8 & 0.4 & 9.2 \\
\hline Russet Norkotah ${ }^{\mathrm{d}}$ & 21.8 & 8.0 & 6.4 \\
\hline Shepody & $\ldots$ & 7.0 & 14.3 \\
\hline Snowden & 1.6 & $\ldots$ & $\ldots$ \\
\hline Superior & 1.8 & $\ldots$ & \\
\hline Yukon Gold & 2.3 & $\ldots$ & 7.7 \\
\hline
\end{tabular}

${ }^{a}$ Wisconsin data were obtained for 2003 to 2010. Summer test PVY level inferred by mosaic symptoms; postharvest PVY level measured with ELISA.

${ }^{b}$ Montana data were obtained for 2001 to 2003 and 2005 to 2010. Summer and postharvest PVY level measured with ELISA.

${ }^{\mathrm{c}}$ Idaho data were obtained for 2009 to 2010. Summer test PVY level inferred by mosaic symptoms; postharvest PVY level measured with ELISA.

${ }^{\mathrm{d}}$ Including the various Russet Norkotah selections. 
significance or explanatory power for individual years using quantile regression; quantile regression models used observations from all three years of the experiment.

For all models, regardless of regression technique or potato variety, the coefficient for seed-borne PVY level is significant at a 95\% confidence level. Of the Russet Burbank OLS models, only the 2011 model has an intercept coefficient significantly different from zero at a 95\% confidence level. Conversely, of the Russet Norkotah models, only the model using the entire 3-year data set did not have an intercept coefficient significantly different from zero at a $95 \%$ confidence level. Of the quantile regression models, only the 75th quantile Russet Burbank model and the 75th and 90th quantile Russet Norkotah models have intercept terms significantly different from zero at a $95 \%$ confidence level.

\section{Discussion}

Our analysis of seed certification data suggests it is difficult to use field inspection results to predict the PVY infection rate measured by postharvest tests with any degree of confidence. In both scenarios investigated, the Montana test results were more consistent than for Idaho or Wisconsin; this is likely owing to the use of laboratory analysis for both in-season inspections and postharvest testing in Montana. Field inspections conducted during the growing season in Idaho and Wisconsin infer the PVY infection level based on mosaic symptoms.

The lower incidence of in-season PVY spread in Montana compared with Idaho and Wisconsin (Tables 3 and 4) may be influenced by the lack of nonseed commercial potato production in Montana. For the 2015 to 2017 growing seasons, $92.9 \%$ of acreage planted in Montana was dedicated to growing seed potatoes, compared with $10.3 \%$ of the Idaho acreage and $12.9 \%$ of the Wisconsin acreage (USDA/NASS).

The analysis of in-season and postharvest test results found some varieties are shown to be more problematic when it comes to inseason PVY spread. High readings from more than one location occurred for the following varieties: 'Alturus', 'Atlantic', 'Dark Red Norland', 'Ranger 'Russet', Russet Burbank, Russet Norkotah,
Shepody, 'Umatilla', and 'Yukon Gold'. Of these varieties, only Russet Norkotah seed had more than $5 \%$ of the samples show PVY infection levels of greater than $2 \%$ in postharvest tests when summer tests indicated infection levels of less than $2 \%$ in all three states of our study.

We considered the share of seed plots with postharvest tests results showing PVY levels of $>2 \%$ whereas the corresponding summer test showed levels of $<2 \% \mathrm{PVY} /$ mosaic (depending on in-season testing methodology used). At the time the data were gathered, this was the PVY tolerance for recertification of seed potato lots in Idaho; certified seed with estimated PVY prevalence above $2 \%$ could not be replanted to grow a subsequent generation of certified seed (although it could still be sold to commercial growers as certified seed). As of 2018, the recertification PVY tolerance in Idaho has been lowered to a $1 \%$ PVY infection rate. Cross-state comparison of these data are limited by the use of laboratory testing in Montana compared with the use of field inspections in Idaho and Wisconsin.

The analysis of in-season and postharvest test results clearly illustrates the need for commercial potato growers to check postharvest test results before they purchase seed potatoes. Perhaps the most important PVY management tool available is to acquire and plant seed potatoes with extremely low or zero levels of PVY; aphids are very efficient at spreading seed-borne PVY across a potato field (Halbert et al. 2003; Verbeek et al. 2010). Failure to consider the postharvest test results of seed potatoes produced in states that use field inspections rather than laboratory tests during the growing season is particularly problematic for commercial growers.

The choice of Russet Burbank and Russet Norkotah for the test plots was appropriate because they account for nearly threequarters of the potato acreage planted in Idaho: 52.5\% Russet Burbank and 20.9\% Russet Norkotah in 2012 (USDA/NASS). These two varieties also vary in the degree of PVY symptom expression. Whereas typical foliar mosaic symptoms from PVY infection are readily observed in Russet Burbank, symptoms tend to be mild or latent in Russet Norkotah. PVY control in Russet Norkotah is more difficult owing to the lack of visual symptoms. During the test-plot experiment, no data on aphid flights was collected; the end-of-season

Table 5. Selected parameter estimates of ordinary least squares regression models of end-of-season potato virus Y (PVY) incidence as a function of seed-borne PVY infection ${ }^{\mathrm{a}}$

\begin{tabular}{llccccccc}
\hline Variety & Model & Intercept coefficient & Intercept $\boldsymbol{\sigma}$ & Seed PVY coefficient & Seed PVY\% $\boldsymbol{\sigma}$ & $\boldsymbol{R}^{\mathbf{2}}$ & Adjusted $\boldsymbol{R}^{\mathbf{2}}$ & Observations \\
\hline Russet Burbank & 3 year & 3.968 & 2.042 & $\mathbf{1 . 2 3 3}$ & 0.079 & 0.820 & 0.816 \\
& 2010 & 1.637 & 1.483 & $\mathbf{1 . 0 7 3}$ & 0.053 & 0.958 & 0.956 \\
& 2011 & $\mathbf{1 1 . 9 3 2}$ & 2.796 & $\mathbf{1 . 2 9 4}$ & 0.099 & 0.905 & 0.900 \\
& 2012 & 0.238 & 1.426 & $\mathbf{1 . 1 9 4}$ & 0.075 & 0.947 & 0.944 \\
Russet Norkotah & $2010 / 12$ & 1.514 & 0.996 & $\mathbf{1 . 0 9 2}$ & 0.041 & 0.955 & 0.954 & 20 \\
& 3 year & 19.850 & 4.494 & $\mathbf{1 . 1 6 4}$ & 0.156 & 0.489 & 0.481 & 36 \\
& 2010 & $\mathbf{1 1 . 2 8 7}$ & 2.152 & $\mathbf{1 . 1 1 3}$ & 0.083 & 0.909 & 0.904 & 20 \\
& 2011 & $\mathbf{5 9 . 2 1 4}$ & 4.836 & $\mathbf{0 . 7 2 6}$ & 0.149 & 0.570 & 0.546 & 20 \\
& 2012 & $\mathbf{3 . 3 4 7}$ & 0.948 & $\mathbf{1 . 0 8 9}$ & 0.034 & 0.982 & 0.981 & 20 \\
& $2010 / 12$ & $\mathbf{7 . 5 8 2}$ & 1.547 & $\mathbf{1 . 0 8 7}$ & 0.058 & 0.903 & 0.900 \\
\hline
\end{tabular}

${ }^{\text {a }}$ Bold entries are significantly different from zero at a 95\% confidence level.

Table 6. Selected parameter estimates of quantile regression models of end-of-season potato virus Y (PVY) incidence as a function of seed-borne PVY infection ${ }^{\text {a }}$

\begin{tabular}{lccccccc}
\hline Variety & Model & Intercept coefficient & Intercept $\boldsymbol{\sigma}$ & Seed PVY coefficient & Seed PVY\% $\boldsymbol{\sigma}$ & Pseudo $\boldsymbol{R}^{\mathbf{2}}$ & Observations \\
\hline Russet Burbank & 10th percentile & 0 & 2.153 & $\mathbf{1 . 0 0 0}$ & 0.083 & 0.616 \\
& 25th percentile & -0.556 & 1.370 & $\mathbf{1 . 1 1 1}$ & 0.053 & 0.622 \\
& 50th percentile & 2.500 & 2.922 & $\mathbf{1 . 1 8 3}$ & 0.113 & 0.583 \\
& 75th percentile & $\mathbf{7 . 5 0 0}$ & 3.434 & $\mathbf{1 . 3 3 3}$ & 0.132 & 0.615 \\
Russet Norkotah & 16.961 & 8.542 & $\mathbf{1 . 2 4 3}$ & 0.329 & 0.575 \\
& 90th percentile & 1.020 & 0.766 & $\mathbf{1 . 1 2 3}$ & 0.027 & 0.496 & 56 \\
& 10th percentile & 2.109 & 2.059 & $\mathbf{1 . 1 5 0}$ & 0.072 & 0.454 & 60 \\
& 25th percentile & 8.00 & 6.858 & $\mathbf{1 . 2 8 0}$ & 0.238 & 0.373 & 60 \\
& 50th percentile & $\mathbf{3 4 . 5 2 6}$ & 11.140 & $\mathbf{1 . 2 0 1}$ & 0.387 & 0.195 & 60 \\
& 75th percentile & $\mathbf{5 9 . 6 4 7}$ & 5.182 & $\mathbf{0 . 9 3 9}$ & 0.180 & 0.154 \\
\hline
\end{tabular}

${ }^{a}$ Bold entries are significantly different from zero at a $95 \%$ confidence level. 
PVY level was analyzed based solely on the seed-borne infection level and a yearly fixed effect (to capture growing season differences in the OLS models).

Quantile regression differs from OLS regression in that the former regresses to the median rather than the mean and uses an absolute error loss function as opposed to a squared error loss function. Quantile regression provides a more efficient estimator when the OLS errors are not normal. Because the seed-borne infection rates in this experiment were high, Quantile regression also allows us to examine the parameters at upper and lower levels of the data, giving us a more complete picture of the rate of spread over the growing season.

Because each test plot contained only 40 seed pieces, the difference between test plots across the treatment levels has a lower bound of $12.5 \% \mathrm{PVY}$, and the finite set $S$ of possible levels of PVY in a test plot is defined as:

$$
S=\{2.5 \% \times k\}_{k=0}^{40}
$$

Of the possible PVY infection levels, only the two lowest values of 0 and $2.5 \%$ are reasonably close to those observed in the certified seed planted by commercial potato growers (Rosenman 2018). The specifics of the experiment used to generate our data dictate that most test plots will have a PVY level of $\geq 5 \%$; a similar experiment that used a significantly larger number of seed pieces per test plot would allow more treatment levels to be within the range of infection levels typically seen by commercial producers.

The models generated from the experimental data support the seed-borne PVY level having a significant impact on the end-ofseason PVY level of a potato field. In a year with high aphid prevalence, even low levels of seed-borne PVY can result in most plants within a field becoming infected (according to our OLS model of the 2011 Russet Norkotah data). Both the experimental data and the models developed from them reinforce the need for commercial potato growers to minimize the PVY level of the seed potatoes they use.

Commercial growers should ask to see postharvest test results before purchasing certified seed potatoes to better asses the quality of their potential purchase. If two seed producers are charging the same price for certified seed potatoes of different quality (in terms of PVY infection level) commercial growers may reap significant economic benefits by being able to make an informed purchase decision.

Seed growers who produce certified seed potatoes with extremely low viral loads may also benefit from sharing postharvest test results with potential buyers. Verification of the quality of their certified seed potatoes may allow these growers to charge a higher price than growers of lower quality seed.

\section{Literature Cited}

Aryal, G. R. 2013. Statewide Impact of Potato Virus Y on Idaho Economy. Master's thesis. University of Idaho, Moscow, ID.

Bonde, R., Schultz, E. S., and Raleigh, W. P. 1943. Rate of spread and effect on yield of potato virus diseases. Maine Agric. Exp. Sta. Bull. 421.

Branham, R. L., Jr. 1982. Alternatives to least squares. Astron. J. 87:928-937.

Cade, B. S., and Noon, B. R. 2003. A gentle introduction to quantile regression for ecologists. Front. Ecol. Environ. 1:412-420.

Cade, B. S., Terrell, J. W., and Schroeder, R. L. 1999. Estimating effects of limiting factors with regression quantiles. Ecology 80:311-323.

Edgeworth, F. Y. 1888. XXII. On a new method of reducing observations relating to several quantities. Lond. Edinb. Dublin Philos. Mag. J. Sci. 25:184-191.

Frost, K. E., Groves, R. L., and Charkowski, A. O. 2013. Integrated control of potato pathogens through seed potato certification and provision of clean seed potatoes. Plant Dis. 97:1268-1280.

Funke, C. N., Nikolaeva, O. V., Green, K. J., Tran, L. T., Chikh-Ali, M., QuinteroFerrer, A., Cating, R. A., Frost, K. E., Hamm, P. B., Olsen, N., Pavek, M. J., Gray, S. M., Crosslin, J. M., and Karasev, A. V. 2017. Strain-specific resistance to potato virus $\mathrm{Y}$ (PVY) in potato and its effect on the relative abundance of PVY strains in commercial potato fields. Plant Dis. 101:20-28.

Gray, S., De Boer, S., Lorenzen, J., Karasev, A., Whitworth, J., Nolte, P., Singh, R., Boucher, A., and Xu, H. 2010. Potato virus Y: An evolving concern for potato crops in the United States and Canada. Plant Dis. 94:1384-1397.

Halbert, S., Corsini, E., and Wiebe, D. 2003. Potato virus Y transmission efficiency for some common aphids in Idaho. Am. J. Potato Res. 80:87-91.

Hane, D. C., and Hamm, P. B. 1999. Effects of seedborne potato virus Y infection in two potato cultivars expressing mild disease symptoms. Plant Dis. 83:43-45.

Karasev, A., and Gray, V. 2013. Genetic diversity of Potato virus Y complex. Am. J. Potato Res. 90:7-13.

Koenker, R., and Bassett Jr, G. 1978. Regression quantiles. Econometrica 46: 33-50.

Mondjana, A. M., Rouse, D. I., and German, T. L. 1993. The impact of PVY on potato yield and severity of early dying. Am. Potato J. 70:829.

Nolte, P., Alvarez, J. M., and Whitworth, J. L. 2009. Potato virus Y management for the seed potato producer. Publication CIS1165. University of Idaho Extension, Moscow, ID.

Nolte, P., Whitworth, J. L., Thornton, M. K., and McIntosh, C. S. 2004. Effect of seedborne potato virus Y on performance of Russet Burbank, Russet Norkotah, and Shepody potato. Plant Dis. 88:248-252.

Rosenman, J. 2018. Seed Potato Certification and Potato Virus Y: An Economic Assessment. Master's thesis. University of Idaho, Moscow, ID.

Schramm, S., Frost, K., Charkowski, A., Gray, S., Crockford, A., and Groves, R. L. 2011. Management of potato virus Y (PVY) in Wisconsin seed potato production. Publication A3951. University of Wisconsin Extension, Madison, WI.

Verbeek, M., Piron, P. G. M., Dullemans, A. M., Cuperus, C., and Van Der Vlugt, R. A. A. 2010. Determination of aphid transmission efficiencies for N, NTN and Wilga strains of potato virus Y. Ann. Appl. Biol. 156:39-49.

Zeng, Y., Fulladolsa Palma, A. C., Houser, A., and Charkowski, A. O. 2019. Colorado seed potato certification data analysis shows mosaic and blackleg are major diseases of seed potato and identifies tolerant potato varieties. Plant Dis. 103:192-199. 